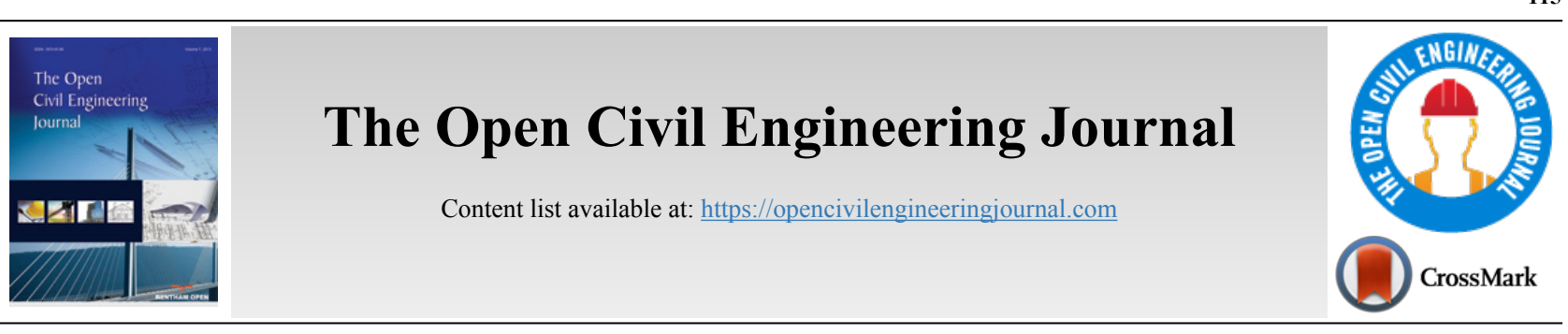

EDITORIAL

\title{
Large Scale Seismic Vulnerability and Risk Evaluation of Historical Centres and Cultural Heritage Constructions
}

\author{
Antonio Formisano ${ }^{1, *}$ and Michele D'Amato ${ }^{2}$ \\ 'Department of Structures for Engineering and Architecture (DIST), School of Polytechnic and Basic Sciences, University of Naples "Federico II", \\ Naples, Italy \\ ${ }^{2}$ Department of European and Mediterranean Cultures, Architecture, Environment, and Cultural Heritage (DICEM), University of Basilicata, 85100 \\ Potenza PZ, Italy
}

The need to protect our cultural heritage from hazardous events, such as earthquakes, is an urgent task for researchers and designers. Firstly, large-scale evaluations for seismic vulnerability estimation of construction sets are required, which can be either of the ordinary type, such as historical centers considered the hearth of our cities, or can have a monumental character, including churches, towers, palaces, villas, etc. These large-scale analyses permit the preliminary assessment of the possible damages that may occur during a given catastrophic seismic event.

To date, in the scientific literature, there are many assessment methods (empirical, mechanical, and hybrid) for seismic vulnerability and risk evaluation of large samples of ordinary or monumental constructions. Some of these are efficient tools in the evaluation of the seismic vulnerability of the built-up of entire cities based on the easily detectable features. At the first stage, geometrical and structural data may be organized in an appropriate survey form, which is dedicated to the rapid investigation of these existing constructions. The collected information is used to assess the vulnerability level of each construction, which is the analysis phase before the seismic risk estimation. These methodologies are characterized by an increasing precision level to prevent and mitigate the related seismic risk, starting from a territorial level evaluation. In this way, a fast evaluation of the expected seismic perfor-mance may be performed, requiring little non-quantitative information, such as damages that occurred in previous seismic events and characteristics of the investigated structures. This first screening is useful for the preliminary ranking of the constructions in terms of seismic vulnerability performance. In this way, detailed investigation through more refined approaches can be prioritized.

\footnotetext{
* Address correspondence to this author at the Department of Structures for Engineering and Architecture (DIST), School of Polytechnic and Basic Sciences, University of Naples "Federico II", Naples, Italy; E-mail: antoform@unina.it
}

In the current special issue, attention is devoted to the global scale analysis of historical centers and cultural heritages through both basic and advanced investigation techniques.

In the paper of Chieffo et al. [1], the municipality of Baranello, located in the province of Campobasso, was considered as a reference study area for assessing the influence of local site effects on the seismic vulnerability of the clustered buildings. The buildings were appropriately grouped in typological classes based on the CARTIS form and then subdivided into different categories according to the EMS-98 scale. A vulnerability-index method conceived for buildings grouped in aggregate condition was applied to each structural unit of the historical center. Due to the variable territory soil stratigraphy, a global increment of the expected damage index was noticed in comparison to the case where geo-hazard effects were neglected. This was also highlighted by typological fragility curves obtained, which were considerably affected in both, epicenter distance and earthquake magnitude.

The paper of Biglari et al. [2] deals with the rapid vulnerability and risk assessment at a territorial level of ten historic masonry mosques in Kermanshah city (Iran) using a quick methodology initially proposed for ancient masonry churches. The comparisons among the obtained results, by considering the damages suffered during the last earthquakes and war blasts as well, validated the methodology proposed. It was capable of providing a seismic risk scoring at a territorial level for ancient masonry mosques. Through this kind of approach, important information was obtained in order to manage and mitigate the seismic risk of a certain territorial and cultural heritage. The obtained results were useful for ranking the priorities and preliminary definition of the design interventions deepened with additional quantitative investigations by more refined approaches.

Finally, in the paper of Zucconi et al. [3], data collected 
during inspections after L'Aquila earthquake, which occurred in 2009 in Italy, were interpreted, accounting for the presence of buildings not inspected due to being undamaged. A novel building damage state, based on the response of different building elements recorded in the survey form, namely vertical structures, horizontal structures, stairs, roof, and partition walls, was proposed. The proposed formulation accounted for typical reparation techniques and a database of complete geometrical surveys, allowing for the estimation of the relative size of the structural elements. Lognormal fragility curves in terms of building damage state grade depending on typological classes and peak ground acceleration were derived and compared with those of previous studies. It was found that the correction of the database to account for uninspected buildings delivers less "stiff" curves, reaching the median for lower peak ground acceleration values. Also, the main building feature that mostly influenced the fragility of inspected constructions was the masonry quality.

\section{CONFLICT OF INTEREST}

The authors declare no conflict of interest, financial or otherwise. Dr Antonio Formisano is the section editor of the TOCIEJ.

\section{ACKNOWLEDGEMENTS}

Declared none.

\section{REFERENCES}

[1] N. Chieffo, A. Formisano, F. Clementi, and M. Mosoarca, "Influence of local site effects on the typological fragility curves for classoriented masonry buildings in aggregate condition", Open Civ. Eng. J., 2021.

[2] M. Biglari, M. D'Amato, and A. Formisano, "Rapid seismic vulnerability and risk assessment of Kermanshah historic mosques", Open Civ. Eng. J., 2021.

[3] M. Zucconi, R. Ferlito, and L. Sorrentino, "Typological damage fragility curves for unreinforced masonry buildings affected by the 2009 L'Aquila, Italy earthquake", Open Civi. Eng. J., 2021.

\section{2021 Formisano \& D’Amato}

This is an open access article distributed under the terms of the Creative Commons Attribution 4.0 International Public License (CC-BY 4.0), a copy of which is available at: https://creativecommons.org/licenses/by/4.0/legalcode. This license permits unrestricted use, distribution, and reproduction in any medium, provided the original author and source are credited. 